\title{
O nascimento como categoria filosófica feminista
}

\author{
Birth as a Feminist Philosophical Category \\ El nacimiento como categoría filosófica feminista
}

\author{
Alice de Barros Gabriel', 2 (iD) 0000-0001-7051-4291 \\ 'Instituto Federal de Goiás, Águas Lindas, GO, Brasil. 72910-733 - \\ gabinete.aguaslindas@ifg.edu.br \\ 2Universidade de Brasília, Programa de Pós-Graduação em Filosofia, Brasília, DF, Brasil. \\ 70910-900 - posfil@unb.br
}

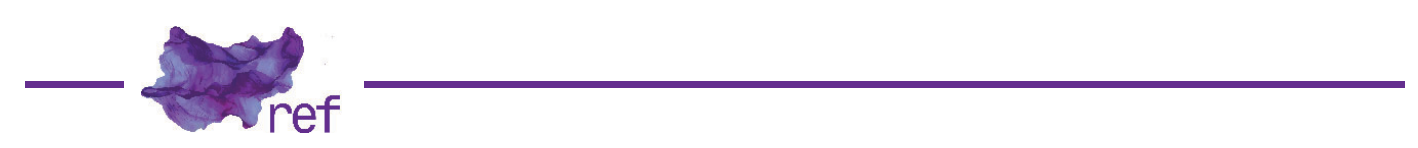

STONE, Alison.

Being Born: Birth and Philosophy.

Oxford: Oxford University Press, 2019. 266 p.

\begin{abstract}
Alison Stone é uma filósofa inglesa, professora da Universidade de Lancaster e especialista em filosofia continental com destaque para o idealismo alemão e teoria feminista. Ela é autora de livros como Petrified intelligence: nature in Hegel's philosophy (2004, SUNY Press), Luce Irigaray and The Philosophy of Sexual Difference (2006, pela Cambridge Press) e An Introduction to Feminist Philosophy (2007, pela Polity Press), e coeditora da coletânea Routledge Companion to Feminist Philosophy (2017, Routledge).

Seu livro de 2019, Being Born: Birth and Philosophy amplia algumas noções contidas no sexto capítulo de An Introduction to Feminist Philosophy (Alison STONE, 2007), tendo como objetivo mostrar que a natalidade é "uma dimensão estruturante de nossa existência"' (Alison STONE, 2019, p. 231). No volume, Stone nos apresenta sete capítulos, nos quais analisa elementos distintos que decorrem do fato de sermos nascidas. O primeiro capítulo explora como o nascimento foi pensado pelas filósofas feministas Luce Irigaray, Adriana Cavarero e Grace Jantzen; os três capítulos seguintes exploram aspectos da condição humana que estão, segundo a autora, conectados ao fato de nascermos: historicidade, vulnerabilidade, dependência, relacionalidade, o fato de nos emaranharmos em redes de poder e nosso caráter situacional resultante. A autora também inclui nesta lista a contingência radical de ser nascida; os dois capítulos seguintes exploram elementos próximos à filosofia existencialista como a angústia causada pelo nascimento e a conexão entre mortalidade e natalidade. O último capítulo se dedica a pensar o nascimento como dádiva a partir do sentido maussiano do conceito. O livro contribui para uma ontologia do nascimento e da relacionalidade constitutiva da existência humana, discute a interseccionalidade em termos de nossas origens natais e dialoga com as teorias contemporâneas sobre o luto.

A ideia de ser humano articulada por Stone se contrapõe à tradição filosófica que identifica no nascimento um espelho para a morte: se morrer é passar do ser ao nada, então
\end{abstract}

" No original: "is a structuring dimension of our existence". 
nascer é passar do nada ao ser. Autoras como Adriana Cavarero (1996) se perguntaram: mas que nada é esse que é um outro corpo como o meu? Stone segue essas pegadas pensando o que significa nascer e quais as implicações filosóficas de levarmos a sério o nascimento. Para a autora, a natalidade humana é uma questão tão relevante quanto nossa mortalidade - na medida que ambas se conectam em nossa finitude - mas que recebeu muito menos destaque na história do pensamento ocidental. Se a tradição filosófica privilegiou a morte, o pensamento feminista tem articulado os termos do que significa ser um corpo que gesta, o que significa ter a capacidade de parir. Hannah Arendt, por sua vez, teria iniciado a discussão sobre a natalidade como conceito filosófico. O conceito de natalidade seria usado de maneira ambígua por Arendt, segundo a autora de Being Born, querendo indicar igualmente o nascimento físico e o nascimento político da diferença. O conceito de natalidade de Arendt foi recepcionado pela filosofia da diferença sexual de Cavarero em sua busca por pensar o apagamento do corpo que gesta. Stone está mais interessada em pensar como nossa experiência é profundamente marcada pelo fato de nascermos, quais aspectos da condição humana decorrem de nosso nascer. Esse é o projeto do livro.

Para Stone, ser nascida quer dizer que começamos a existir em um tempo e um espaço definido, chegamos no mundo como um corpo que tem marcadores sociais específicos de nossa cultura e história e, antes de chegarmos, fomos concebidas, gestadas e paridas por um outro corpo humano. Stone faz questão de ressaltar que, embora historicamente esse corpo gestante tenha sido identificado como corpo materno e, portanto, feminino, as gestações de homens trans e também práticas como gestação por substituição ampliam o escopo do corpo gestante para além do que o termo "maternidade" costuma significar (STONE, 2019, p. 1-2).

Que aspectos da existência humana tem fundamento em nossa natalidade? Para Stone, um primeiro aspecto é a dependência. Intrinsecamente conectado à nossa identidade enquanto espécie, pois é na altricialidade que Stone vai encontrar o fundamento material para nossa dependência constitutiva. A altricialidade é uma marca que partilhamos com várias outras espécies - como marsupiais e aves, por exemplo. Entre os animais vivíparos a altricialidade depende do desenvolvimento do cérebro quando do nascimento. É sabido que a bipedestação humana é causa de um dilema obstétrico na aurora da humanidade: pélvis se tornando mais estreitas pela postura ereta, enquanto os cérebros se tornavam maiores. Assim, tal dilema resultou no nascimento de indivíduos com cérebros pouco desenvolvidos e com uma inacreditável plasticidade para o desenvolvimento posterior. Isso resulta no fato de seres humanos nascerem bastante vulneráveis necessitando de uma segunda gestação externa ao útero. Assim, segundo Stone, a altricialidade é mais proeminente nos humanos devido às habilidades mentais e práticas que precisam desenvolver ao longo de suas vidas. O custo do desenvolvimento cerebral é a vulnerabilidade acentuada no início da vida.

Esse aspecto altricial entra em contraste com o sujeito autônomo, emancipado, autossuficiente que caracteriza a filosofia moderna. Antes de ser um reforço a uma excepcionalidade humana, o apelo à altricialidade explica o ser-para-comunidade dos seres humanos em termos naturais e não em termos de transcendência ou artificialização. Como pássaros e marsupiais, precisamos de arranjos sofisticados para o cuidado ao nascermos, tais arranjos compõem nossa história individual e a história de nossa espécie. O cuidado, necessário para responder à altricialidade, está arranjado coletivamente na instituição de arranjos de parentesco. Tais arranjos culturais variam bastante nos grupos humanos - desde arranjos coletivos até a privatização do cuidado na família nuclear instaurada como modelo na modernidade.

Reconhecer a natalidade implica outro registro da condição humana. Sendo dependentes, somos relacionais. Nascemos de outro corpo e ingressamos em um mundo de relações já constituídas e a se constituírem através de nossa integração. Nossa percepção de nós mesmas se dá através das relações e interações uns com os outros. É o estar-com que molda quem nós somos: compostas por relações. Também a atenção à natalidade nos faz rever a ideia da mortalidade. Para Stone, nem mesmo a morte é uma experiência individual. 0 luto evidencia justamente nossa relacionalidade, na medida que perder alguém é perder um pedaço dessa rede que nos constitui e, portanto, perder um pedaço de si. No livro, a conexão entre vulnerabilidade e luto poderia ser mais explorada pela autora, ampliando a discussão da finitude a partir de uma ontologia relacional.

Reconhecer a natalidade implica reconhecer também a situacionalidade: não há nascer abstrato. Todo nascimento é situado. A filósofa argumenta que cada situação de nascido é única e forja o primeiro pano de fundo de quaisquer escolhas individuais. Esse primeiro determinismo da situação social, histórica e cultural marca todas as nossas escolhas futuras. Stone se move num âmbito existencialista nessa altura do argumento - mobilizando autores como Jean-Paul Sartre e Martin Heidegger -, mas é possível entender como essa discussão é ampliada com o próximo elemento: as dinâmicas sociais de poder. Todo corpo que nasce se integra numa complexa rede de relações e de poder. 
Stone chama atenção que todos esses elementos elencados em sua leitura da condição humana - dependência, relacionalidade, situacionalidade e enredamento em relações sociais de poder - foram analisados anteriormente por feministas, mas normalmente desarticulados entre si. Sua análise busca conectar os elementos anteriores através do nó do nascimento. Essa seria sua contribuição para o debate, ao articular elementos que aparecem de maneira difusa em uma antropologia filosófica com o foco no ser nascido.

A discussão sobre novas tecnologias reprodutivas não são centrais para a empreitada de Stone. A autora sugere que essas questões dizem respeito ao fazer nascer e não ao nascimento. Entretanto, é possível pensar como as novas tecnologias têm potencialidade de reestruturar o parentesco, o que poderia representar uma mudança significativa na experiência de ser nascida. Marilyn Strathern sugere que as "possibilidade contemporâneas de procriação artificial introduzem novos contrastes entre os processos artificiais e naturais"2 (Marilyn STRATHERN, 1992, p. 20) e, uma vez que o parentesco é, ele mesmo, uma combinação entre os domínios da cultura e da natureza, um deslocamento é efetuado.

Sobre a ideia de ectogênese, ou gestação ex utero - apresentada como um caminho para a libertação feminina em Shulamith Firestone (1972) e como a abolição do gênero em Marge Piercy (1979) - Stone defende que se houvesse um avanço tecnológico substancial permitindo uma gestação mecânica, isso não alteraria a dinâmica do cuidado humano. Entretanto, tal resposta parece ignorar a potencialidade da ectogênese em resolver o dilema obstétrico acabando com a altricialidade característica de nossa espécie. Um cenário de ficção científica de gestação artificial ampliada tiraria o cuidado da centralidade de nossa experiência enquanto nascidas de outros corpos.

O livro contribui bastante para pensar o nascimento no âmbito da teoria feminista. Não o gestar, não o parir, mas o nascer e o nascimento. Outros textos, como o clássico "Of Woman Born" de Adrienne Rich ou o já mencionado "Dire la nascita" de Adriana Cavarero, se debruçaram sobre o nascimento, mas com o foco naquela que gesta, na experiência de dar origem a outro ser humano. Stone se preocupa em pensar qual impacto o nascimento tem na existência de cada uma de nós, que somos igualmente nascidas? Assim, ela explora uma área pouco discutida na filosofia, ampliando a noção de finitude, para além da discussão sobre a morte e o morrer, entendendo também o nascer como um limite temporal da existência. Trata-se de um livro relevante para teoria feminista, bem como para as discussões sobre o existencialismo de maneira mais ampla.

\section{Referências}

CAVARERO, Adriana. "Decir el Nacimiento". In: DIOTIMA. Traer al mundo el mundo: objeto y objetividad a la luz de la diferencia sexual. Madrid: Icaria Editorial, 1996. p. 130-135.

FIRESTONE, Shulamith. The Dialectic of Sex: The case for feminist revolution. New York: Bantam Book, 1972.

PIERCY, Marge. Woman on the Edge of Time. London: The Women's Press, 1979.

STONE, Alison. Being Born: Birth and Philosophy. Oxford: Oxford University Press, 2019.

STONE, Alison. "Birth". In: STONE, Alison. An Introduction to Feminist Philosophy. Cambridge: Polity Press, 2007. p. 167-191.

STRATHERN, Marilyn. Reproducing the Future: essays on anthropology, kinship and the new reproductive technologies. Manchester: Manchester University Press, 1992.

Alice Gabriel (alice.gabriel@ifg.edu.br, alicegabriel@gmail.com) é bacharela, mestra e, atualmente, doutoranda em Filosofia pela Universidade de Brasília (UnB), desenvolvendo pesquisa sobre novas ontologias feministas. É professora do Instituto Federal de Goiás (IFG), Campus Águas Lindas.

\footnotetext{
${ }^{2}$ No original: "Contemporary possibilities of artificial procreation introduce a new contrast between artificial and natural process".
} 
COMO CITAR ESTE ARTIGO DE ACORDO COM AS NORMAS DA REVISTA

GABRIEL, Alice de Barros. "O nascimento como categoria filosófica feminista". Revista Estudos Feministas, Florianópolis, v. 30, n. 1, e83481, 2022.

\section{CONTRIBUIÇĀO DE AUTORIA}

Não se aplica.

\section{FINANCIAMENTO}

Não se aplica.

CONSENTIMENTO DE USO DE IMAGEM

Não se aplica.

\section{APROVAÇĀO DE COMITÊ DE ÉTICA EM PESQUISA}

Não se aplica.

\section{CONFLITO DE INTERESSES}

Não se aplica.

\section{LICENÇA DE USO}

Este artigo está licenciado sob a Licença Creative Commons CC-BY 4.0 International. Com essa licença você pode compartilhar, adaptar, criar para qualquer fim, desde que atribua a autoria da obra.

\section{HISTÓRICO}

Recebida em 22/08/2021

Aceita em 07/12/2021 